PATHOLOGICAL 'REMARKS ON A CASE OF HEPATITIS RESULTING IN ABSCESS.

By Eduond Bourt, Esq., Fellow of the Royal College of Surgeons of England, H.P. Bengal Medical Service; Assistant Surgeon to the Eye Infirmary, Bath.

(Read at the December Meeting of the Bath Pathological Society.)

J.B. a woman, aged 53 , of a very full habit of body, and accustomed to live freely, applied to me on the 18th of October, 1845, suffering from congestive dyspepsia. She was generally speaking healthy, but had suffered in her lifetime from inflammatory disease in the chest. She was freely purged with mercurials and saline aperients; low diet was enjoined, and in a few days she was well again; but on the 1 th of November, without any assignable cause, (except perhaps an excess of diet, which was not acknowledged,) she was suddenly seized with rigors, followed by the usual symptoms denoting acute inflammation of the liver. The pain was $s 0$ very acute and so sensibly increased by the slightest touch or pressure, as to lead to the supposition that the peritoneal coat of the right lobe was principally engaged. From the first onset of the disease the urine was completely loaded with lithate of ammonia, so much so as for the first few hours afict it was passed, to have the appearance of a brick-red liquor, without any sediment, but afterwards the deposit was thrown down and the fluid assumed a yellowish tinge.

The disease was met very actively, with the uswal treatment, which it is not my purpose to dwell upon. I will just observe, that she was freely bled, locally and from the arm, afterwards blistered, freely purged, her system brought rapidly under the influence of mercury, and a strict antiphlogistic regimen enforced; by these means the pain was mitigated, but the in flainmation instead of subsiding altogether as was desiled, gradually assumed a sub-acute character, and was not to be orercome.

Under these circumstances, abscess was the result naturally to be expected, and accordingly about the beginning of Jauuary, 1846, she was again seized with rigors, followed by pulsation or throbbing in the hypochondrium. By the 10th of the same month, the side was tumefied, and fluctuation was readily perceived. The patient, however, was much exhausted; her pulse was 96. On the 11th it had risen to 120, was hard and jerking, betraying in itself the existence of pus, pent up in the system. On the 12th she was troubled with constant bilious vomiting; her countenance was anxious, and it appeared that if she were not relieved in a few hours, death must be the inevitable result. Still she had naturally a good constitution, and there was reason to think, that if freed from accumulating pus, she might rally.. Her pulse this day was not to be counted, as she had heen hurried getting up to stool; the evacuation being of normal character. I must not omit to mention, that at this time, since the setting in of suppuration, the urine had regained a healthy appearance, and was free from all deposit.

Under these circumstances, with concurrent ralued advice," selecting the softest and most depending situation, on the outer side of the hypochondrium, I passed a trocar obliquely upwards and inwards into the carity of the abscess, and evacuated nine ounces (by weight,) of pus, mingled with bile, and then placed a small tent of lint in the wound.

The patient was faint, and suffered much from bilious vomiting, but on the whole was reliered. She slept and took nourishment, and in the evening her pulse was 100, soft and equable.

On the 13th I removed the plug, as no pur escaped through it, and took away five ounces more. of similar looking pus to that evacuated the previous day.

'The patient still suffered for some days from bilious romiting, which was rery troublesome to manage. The abscess continued to discharge freely and the fluid evacuated seemed to consist of as much bile as pus, and the urine again threw down large deposits of the lithate of ammonia. Once or twice $I$ thought it contained bile, but this was not tested.

The sinus was very difficult to keep open, the external orifice getting frequently glued up, but as soon as any quantity of pus re-accumulated, she became evidently feverish, and altogether worse. Howerer, she gradually improved, and on the 12th of February, a month after the puncturing, I explored the sinus, and found it three inches and a half deep; but as far as I could detect, the cavity of the abscess was nearly obliterated. On the 16 th the discharge had almost ceased, and $I$ allowed the orifice to remain closed, in hopes that the sinus would become sound throughout its extent. On the 22nd, deposits ceased in the urine, though on the 25 th, it was again loaded.

The patient was now able to move into an adjoining roon, though her pulse kept at 105, and she continually complained of cold, and had nearly lost the use of her limbs from paralysis.

Shortly after this she went into the country, and was not under my eye. There I learned that some degree of pain recurred in the side, and it became again tumified, the sinus re-opened and a similar evacuation, as regards quantity and quality, was discharged as on the former occasion.

She returned home after an absence of fifteen weeks. When I examined her, I found the wound still wept a little serum, her pulse was 100 , and she was nearly hemiplegic, but her appetin was good and tongue clean. I gave her very little medicine and she began to improve. In Angust her pulse cause down to 84 ; her side was free from all tumour or tenderness; the sinus was quite closed; her general health much improved; and she was recorering the use of ber limbs. When I saw her a few weeks ago, she was enjoying a very fair state of health. She bas again returned to the country and I was inforfned a few days since, that she continues to regain more of her original good health, and has discarded her crutches; but I must not omit to mention, that occasionafyy, siight tumidity recurs in the side, and a fluid resenubling pure serum

- My friends Drs. Bowie and Fergueson, and Mr. Underhay, were so good as to see this case with me, and agreed as to the necessity of puncturing the abscess. 
oozes from the sinus in sufficient quantity to moisten her clothes; in other respects she has nothing to complain of.

Iraving briefly sketched the history of this case, I proceed so make a few pathological remarks on the disease. When inflanmation of the liver of an acute or sub-acute character bas existed for any length of time, we know that suppuration is not an infrequent result, and the diagnosis of abscess, generally speaking, is not difficult; except perhaps in that form which is described as occurring most frequently in scrofulous constitutions, where a number of small abscesses, aboút the size of a filbert each, are scattered throughout the substance of the organ; and it may occur, that in cases where fluctuation is readily perceived the pus may be contained in two or more distinct sacs not communicating with each other. Such a circumstance would occasion serious embarassment if relief were attempted by external puncture.

In the present case suppuration was ushered in with rigors, though they are by no means its invariable concomitants. In those cases where the disease progreses insidiously, or where pus is laid down secondarily in connection with dysenteric disease, rigors āre generally absent. This circuunstance tends to make the exact diagnosis more difficult. I have frequently, in examin. ing the bodies of Europenn soldiers of Her Majesty's Regiments in Bengal, been surprised to find immense collections of pus in livers, where its presence had not been suspected, though in relation to this subject, the late Mr. 'Twining, a very high authority, says,- "I believe there are always symptoms, which though obscure, are always sufficient to point out the disease." (Diseases of Bengal, Vol. I., p. 29.)

The patient's pulse was quick, small, and jerking, indicating pus being pent up in the system. Increased tumefaction and a sense of fluctuation were soon perceptible in the hypochondrium, and these symptoms are always to be expected when the disease is situated superficially. It is only in the "deep central abscess" that obscurity is likely to occur.

The mere circumstance of pus being formed in the substance of the liver, even with a tendency to travel outwards, affords no guarantee that adhesive inflammation will occur between the opposed layers of the peritoneum; but in this case there was great reason to suppose, from the great pain and tenderness at the onset, that the peritoneal coit was primarily engaged, and this led me to infer that no danger of extravasation into the cavity of the membrane would occur, if an external opening were made, to give exit to the confined pus. The abscess was clearly situated in the superficial portion of the right lobe, and Nature was endearouring to affect her own cure by tending to a discharge externally; but it was evident that the patient's constitution could not afford to wait the result of Nature's own operations, and it became necessary to assist her, otherwise in a few hours death would haw occurred from exhaustion; or it appeared possible that the abscess might burst into the peritoneum, $-\mathbf{a}$ result not by any means so infrequent as some have supposed, especially in India, where the patients usually die within a period rarying from a few hours to a few days.

Assuming Dr. George Budd's opinion to be correct, that the prognosis of hepatic abscess is m.ore unfavourable, generally speaking, when it is discharged immediately externally through the abdominal walls than by any other channel, it is very important to mark what are those conditions which seem most likely to promise a favourable result; and amongst the most evident is the circumstance of the abscess being situated superficially, because then there is most likely to be a less amount of disorganization, and then there is by far the greater probability of adhesions being formed between the layers of the peritoneum, the want of which is a very certain drawback to the success of any operation, and I am doubtful whether Dr. Graves' or any other method offers any certainty of producing such adhesions.

The quantity of pus eracuated was not great; nine ounces, by weight, seemed to empty the sac. We know that the amount of softening and sero-purulent infiltration with which abscess commences, is proportioned to the intensity of the engorgement and subsequent inflammation; and it is evident that they must equally depend upon the amount of structure engaged. Thus, I presume, only a portion of the organ was inflamed in this instance.

The pus discbarged was clearly mingled with a large proportion of bile; and I would ask,-was this bile secreted by the walls of the abscess, or was it infiltrated through them from the surrounding parenchyma? It might be supposed that the gall-bladder was injured; but in another case, where large quantities of bile were discharged externally, and the patient died, the gallbladder was found intact. Perhaps the more probable supposition is, that a large duct was opened by the process of ulceration, and that it refused to take on a reparative action, and so allowed the bile to escape.

The operation was succeded by romiting. On this symptom I will remark presently.

Long after the patient had rallied from the primary attack the pulse contianed high; and although she ate and drank, and slept well, and the side was free from all tenderness, still there can be no doubt that inflamination of a low sub-acute character was going on. Suppuration is a result which relieves and checks inflammatory action, but by no means vanquishes it; and this low inflammation ultimately produced a secondary formation of pus in sac of the abscess, at which time the patient was not ander my eye; but there is great reason to suppose that the original inflammation had never been entirely subdued, and it existed, I believe, without prodweing pain. The liver itself is not highly susceptible of pain, and I 
apprebend that the very painful symptoms in hepatitis are mainly dependent upon the tension, inflammation, or sympathy of its serous investment.

The character of the urine next demands an obserration or two. From the first attack of the disease the urine was marked by large deposits of lithate of ammonia, distinguished by a great amount of colouring matter being developed with it, so much so as to give it the appearance of that very scarce kind, which is described as being pernanently red, and which throws down no deposit. Its specific gravity was rather low, 1.014, at a temperature of $60^{\circ}$, and it contained no alhumen.

Deposits of lithate of ammonia are very comuron in hepatic disease, and I need no apology for quoting Dr. Prout's views on the subject. He says "the lithate of ammonia is not only supposed to be derived from imperfectly assimilated chyle, but aiso from the deranged secondary assimilation of the albuminous textures of the body." (Stomach and Renal Diseases, p. 203.) He considers that the liver not only performs a negative or excretory function, but also a positive or assimilating power orer the oleaginous tissues. The following are his general inferences on this subject:-

"First, 'the liver is the organ by which the blood is depurated of unassimilated and superfiuous oleaginous matters, as well as of those portions of the blood deprived of its azote, of its saccharine constituents, and consequently of its vitality, during the primary assimilating processes. Secondty the kidneys are the organs by which the blood is depurated of its unassimic lated, superfluous, and effete albuminous principles, as,well as of the mineral matters incidental to these principles which are otherwise derived. Thirdly, the neutral and alkalecenat character of the bile, and the oxygenated and acitalous character of the urine, shew that the general chancters of the actions going on in the lirer and kidneys are opposed to each other; - in short, that the general action of the liver is of a negative, the general action of the kidneys of a positire, character; and that one of these important organs, antagónistically related to each other, cannot be ceranged without deranging the other." (Op. cit., p. 569.) To this he adds a foot note- "This deduction may be stated more generally, thas :-The liver may be considered as the principal focus or pole of all the negative; the kidneys as the principal focus or pole of all the positive actions going on throughout the organic system."

During the continuance of certain hepatic and other diseases, the process of assimilation is interfered with, and lithates are largely eliminated by the kidneys, Now, in the present case, I have before remarked, that on the setting in of suppuration, all deposit ceased in the urine. How is this phenomena to be explained ? $I$ appreliend that during the progress of the disease the lirer was in a state of intense engorgement, which completely interfered with the due performance of its normal functions. This engorgement was partially relieved by the pouring out of pus. The organ freed from an overpowering incubus, immediately resumed its proper office, and bile was secreted in an inordinate quantity, which was the cause of the troublesome romiting already alluded to, and which was quite distinct from the vomiting of irritation which occurs where abscess is situated near the inferior surface of the organ. The kidneys then ceased to eliminate the abnormal quantity of lithate of ammonia, and the balance of secondary assimilation for the tine was restored. After a while the engorgement again took place, the relief being temporary; the lithate was again thrown down in the urine, and continued with slight intermission until convalescence proved that the entire function of assimilation was satisfactorily performed. I regard this as interesting in a pathological point of view, and corroborative of Dr. Prout's hypothesis.

There is another point to which I must just refer, without at all entering into the question. The patient from the time the abscess was opered, complained continually of a sensation of chilliness, even whiks the surface of ber body to the touch felt hot and dry. Now, this symptom may, I think, be taken with the paralytic affection, and be considered as arising from impaired nervous energy, consequent upon so severe an attack of disease in 80 important an organ. But on the other Land it may be that this symptom was connected with an interesting question. If the views of some authors be correct, we may enquire how far the function of combustion, the evolution of caloric, was interfered with by this lesion of the liver; but this rather belongs to physiology than pathology, and I shall not attempt to enter upon it now.

Lastly, the question may be asked,-What is the present condition of the organ?

The past-mortem examinations of individuals who have died several years after recovery from hepatic abscess, have discorered no remains of the disease, excepting sometives the existence of adhesions between the opposed surfaces of the peritoneum, and I believe in most cases the sac is perfectly obliterated. How is this effected? In similar cases, abcesses have been found difficult to heal, and some practitioners have attempted to close them by exciting adbesive inflammation in the sides of the sac; but suppurating, like wucous, surfaces, do not readily take on inflammation of an adhesive character, and the attempt has usually failed. The process of obliteration is, I believe, accomplished gradually, as the abscess was formed. As in the latter case absorption increased around the primary softening and intiltration; so afterwards, new healthy parenchymatous structure is laid down, gradually lessening the area of the sac, until nothing but the walls remain; these are at last absorbed themselres, and the organ regains its original integrity of structure. Where the 
peritoneum bas been inflamed, as in the present case, doubtless adbesions will be formed, but Mr. Twining remarks, that it, is surprising how seldom they do exist, even in cases where the abscess was situated superficially and tended towards an exit through the abdominal parietes. Have I a right, then, to suppose that the liver in this case has recorered its original integrity? The only suspicious circumstance which leads me to doubt at all, is the occurrence of the occasional tumidity and serous oozing; and yet I can hardly think that the sac is still in existence, and rather believe that the oozing may be derived from the remains of the sinus. Be this as it may, I do not feel inclined to attempt to decide the question by the introduction of a probe, but enjoining the woman to take the strictest care of berself as regards diet, and exposure to wet or cold, I leave the matter for time to elucidate.

Batb, December, 1846.

\section{CASE OF AMPUTATION OF THE THIGH} UNDER THE INFLUENCE OF ETHER.

TO THE EDITOR OF THE PRONINCIAL MEDICAL AND Sir, SCRGICAL JOURNAL.

As the medical profession at this moment must fetl deeply interested in the late discovery made by our Transatlantic friends, of the inhalation of æether producing that state of narcotism which renders persons insensible to the pain arising from surgical operations, I offer no apology for sending you the following bi ief account of an experiment as to its effect, which came under my own observation yesterday. My partner, Mr. Coleman, haring occasion to perform amputation of the thigh upon a young woman of a higbly nerrous temperament, and who dreaded the pain of the operation exceedingly, wo deemed it a favourable opportunity to test the efficacy of this new discovery. By the kind assistance of Mr. Julion, a talented young chemist, we prepared the necessary apparatus to conduct the experiment. The patient being brought to the edge of the bed, the tourniquet applied, and everything prepared to com. mence amputation, she began to inhale the æther, which produced a good deal of coughing, and it was with some difflenity we prevailed upon her to persevere, which she at length did;-not, however, in a very satisfactory manner, drawing only short inspirations, and then remoring the tube from her mouth. After using it for the space of three or four minutes, her teeth became fixed, her eyes closed, and she sank back into the arms of an attendans, as if in a state of complete intoxication. Mr. Coleman now siezed this favourable moment, and very adroitly and expeditiously performed the flap operation. The patient struggled with ber hands, and cried out for her mother, (who had been dead some years.) The sound limb was not held, nor did she move it, bat frequently said "she, would not have ber leg cut off then;" indeed it was quite orideat she was not aware of the operation being per- formed; for atter the stump was dressed, and she was comfortably placed in bed, she said "it was not off, for ber foot was asleep," and begged of some of us to rub it. On enquiring of her, some hours after the operation, what she had felt, she said "she thought she had been in a dream, and that we had hurt her leg, to see if she could bear the operation, which was to be performed the next day." She had no recollection of any cutting pain, nor could she tell the kind of pain she had suffered, but thonght she remembered "hearing the bone sawed."

The narcotic effect of the æther soon subsided; for in putting in some sutures to bring the edges of the stump together, the passing of the neodle through the skin, produced cries of the most agonizing pain, though her mind was not sufficiently restored to consciousness, to be aware of what was going on.

The result of this trial I cannot but think highly encouraging; and fully beliere, that if the inbalation had been more perfectly accomplished, the state of insensibility would have been most complete. So satisfied am I, that we now possess a means of narcotizing pain, that $I$ shall not hesitate to adopt it in any caso where a painfnl sargical operation has to be undergone, taking care in future to render my patient thoroughly conversant with the mechanical process of inhalation, previously to the use of the ather.

I remain, Sir,

Your obedient serrant, GEORGE EDWARDS.

Wolverlıampton, Jaí. 2, 1847.

P.S. January 3rd. Our patient is going on very favourably, and still perșists she had a dream during the operation.

\section{Tospital Reports.}

CLINICAL REPORTS OF SURGICAL CASES UNDER THE TREATMENT OF WILLIAM SANDS COX, ESQ., AT THE QUEEN'S HOSPITAL, BIRMINGHAM.

By Peter Hinckes Bird, one of the Resident Medical Officers.

\section{Case XVIT.}

FRACTURE OF THE BASE OF THE SKOLL.

William Stock, aged 41, admitted July 11 th into the Queen's Hospital, at half-past four o'clock p.m. He is a guard upon the Gloucester Railway, and is a very tall powerful man. It is stated that while the train from Gloucester was going along at full speed, he, was stauding with his back to the engine, on some luggage on the top of one of the carriages, and on going under an archway his head struck against the arch with great force. He immediately fell down insensible. He lost a considerable quantity of blood from a wound of the scalp before his admission.

When admitted he was in a complete state of coms, with stertorous breathing; dilated pupils, insensible to the stimulus of light; total loss of sensibinty, and of power orer the voluntary muscles; extremities cold, 